\title{
CONCRETO DOSADO COM SUBSTITUIÇÃO PARCIAL DO AGREGADO GRAÚDO POR RESÍDUO DE MINERAÇÃO DE CARVÃO DA REGIÃO CARBONÍFERA DE SANTA CATARINA
}

\author{
DA VEIGA GERMANI, MARIA EDUARDA \\ Estudante \\ Universidade do Vale do Itajaí \\ Santa Catarina, Brasil \\ mariaegermani@gmail.com
}

\author{
MIRIELE SCHIESSL DINIZ, VICKI \\ Estudante \\ Universidade do Vale do Itajaí \\ Santa Catarina, Brasil \\ vickimiriele@hotmail.com
}

\author{
SANTOS, SÍLVIA \\ Professora \\ Universidade do Vale do Itajaí \\ Santa Catarina, Brasil \\ ssantos@univali.br \\ CRISTIANO CAPELARI, CAIO \\ Engenheiro Civil \\ Universidade do Vale do Itajaí \\ Santa Catarina; Brasil \\ caioccapelari@gmail.com
}

\section{RESUMO}

O carvão mineral existe há milhares de anos em depósitos de origem vegetal, formado por meio da decomposição da matéria orgânica sem a presença de oxigênio, e tendo, como o seu principal composto, o carbono. No Brasil, a mineração do carvão se concentra principalmente na região Sul, e apesar de se extrair e beneficiar toneladas deste material anualmente, a produção de resíduo pode chegar até $70 \%$ do volume total extraído, segundo dados do Sindicato e Indústria de Extração de Carvão do Estado de Santa Catarina (SIECESC, 2016). Os depósitos destes resíduos são a principal fonte de geração de drenagem ácida de mina (DAM), oxidação que consiste na reação dos minerais sulfetados ao contato com água e oxigênio atmosférico. Há dificuldades para coletar, tratar, transportar e dar a disposição naturall correta a estes resíduos. Assim, o objetivo deste trabalho foi caracterizar o resíduo do carvão mineral da região sul do estado de Santa Catarina para seu reaproveitamento como agregado para produção de concreto, analisandoalgumas de suas características mecânicas, físicas e químicas. As características requeridas do concreto foram resistência característica de $40 \mathrm{MPa}$ e abatimento de tronco de cone $(100 \pm 2) \mathrm{mm}$. Os concretos produzidos com os diferentes teores de resíduo atingiram a trabalhabilidade fixada, sem a necessidade do uso de aditivos. Todavia, o aumento do teor do resíduo de carvão mineral nas misturas, levou a uma redução de resistência mecânica aos 28 dias; aumento do módulo de elasticidade; e aumento da massa específica, indicando que o material tem potencial para ser utilizado em concretos, porém demanda mais estudos para o entendimento de suas propriedades.

Palavras-Chave: carvão mineral, resíduos sólidos, reaproveitamento, concreto.

\section{ABSTRACT}

Mineral coal has existed for thousands of years in deposits of vegetable origin, formed by decomposing organic matter without the presence of oxygen, and having carbon as its main compound. In Brazil, coal mining is concentrated mainly in the South region, and despite the fact that tons are extracted and processed annually, the production of waste can reach up to $70 \%$ of the total volume extracted, according to data from the Union and Coal Extraction Industry. of the State of Santa Catarina (SIECESC, 2016). The deposits of these residues are the main source of generation of acid mine drainage (AMD), oxidation that consists of the reaction of sulfide minerals on contact with water and atmospheric oxygen. There are difficulties in collecting, treating, transporting and giving the correct naturall disposal to this waste. Thus, the objective of this work was to characterize the mineral coal residue from the southern region of the state of Santa Catarina for its reuse as aggregate for the production of concrete, analyzing some of its mechanical, physical and chemical characteristics. The required characteristics of the concrete were characteristic resistance of $40 \mathrm{Mpa}$ and reduction of the Slump Test $(100 \pm 2) \mathrm{mm}$. The concretes produced with the different levels of waste reached the fixed workability, without the need for the use of additives. However, the increase in the content of coal residue in the mixtures, led to a reduction in mechanical strength at 28 days; increased modulus of elasticity; and an increase in specific mass, indicating that the material has the potential to be used in concretes, but it requires more studies to understand its properties.

Keywords: mineral coal, solid waste, reuse, concrete. 


\section{INTRODUÇÃO}

Segundo a Associação Brasileira de Carvão Mineral (ABCM, 2016), a ocorrência do carvão no Brasil encontra-se predominantemente na região sul, com o Rio Grande do Sul produzindo 28 bilhões de toneladas, Santa Catarina com 3,3 bilhões de toneladas e o Paraná produzindo 104 milhões de toneladas, sendo usado como matéria-prima para fabricar aço nas siderúrgicas e para produzir energia elétrica em usinas termelétricas.

Além de ser o tipo de carvão mineral mais abundante na natureza, é usado em grande escala devido a sua alta eficiência energética, o qual está diretamente ligada a quantidade de carbono presente na composição: quanto maior o teor de carbono, mais puro é considerado. Todavia, esse processo resulta em uma geração de resíduo que pode chegar a $70 \%$ do volume total extraído, segundo dados do Sindicato e Indústria de Extração de Carvão do Estado de Santa Catarina (SIECESC, 2016). Esse resíduo, por sua vez, é responsável pela principal fonte de geração de drenagem ácida de mina, (DAM), que é um "fenômeno que se inicia quando rochas contendo minerais sulfetados são retiradas do interior da terra pelas atividades de mineração e, quando dispostas na superfície terrestre, oxidam-se por reação com água e oxigênio atmosféricos" (MELLO; DUARTE; LADEIRA, 2014, p. 24).

Os prejuízos que a contaminação gerada por meio deste ácido causa são inúmeros, com destaque para a dificuldade de revegetação em áreas de mineração e a alta variação nos valores de pH destes solos.

Deste modo, pensando em aplicações para este resíduo que possam colaborar para redução do passivo ambiental das beneficiadoras de carvão mineral, bem como com a redução de extração de matéria-prima virgem para a produção de concreto estrutural, o objetivo do trabalho foi investigar o comportamento mecânico do concreto estrutural com a substituição parcial de agregado graúdo por resíduo de mineração de carvão da região carbonífera de Santa Catarina.

\section{METODOLOGIA}

O material principal da pesquisa, o resíduo da mineração de carvão da região carbonífera de Santa Catarina, foi disponibilizado pelo depósito da Carbonífera Metropolitana S.A. (Treviso - SC). Sua coleta seguiu o que preconiza a NBR 10007 (ABNT, 2004), sendo feita em uma única vez, tendo sido, posteriormente, seco ao ar.

O resíduo de carvão mineral coletado foi submetido a peneiramento mecânico a fim de se utilizar, na produção dos concretos, apenas a faixa granulométrica que compreende os agregados graúdos.

Já o cimento (CPII F 40); agregados graúdos (brita 0 e brita 1), agregados miúdos (areia natural e artificial); e aditivo (polifuncional da marca MATCHEM tipo Maximent MX 100) para a dosagem do concreto, foram concedidos pela central de dosagem de concreto Polimix, localizada na cidade de Camboriú - SC. Todos esses materiais também foram coletados em uma única vez. As normas utilizadas na caracterização dos agregados estão indicadas no Quadro 1.

Quadro 1: Normas utilizadas

\begin{tabular}{|l|l|}
\hline \multicolumn{1}{|c|}{ Norma } & \multicolumn{1}{c|}{ Descrição } \\
\hline ABNT NBR NM 53, 2009 & $\begin{array}{l}\text { Agregado graúdo - Determinação da massa específica, massa específica aparente e } \\
\text { absorção de água }\end{array}$ \\
\hline ABNT NBR NM 53, 2009 & Agregado miúdo - Determinação da massa específica e massa específica aparente \\
\hline ABNT NBR NM 45, 2006 & Determinação da massa unitária no estado solto \\
\hline ABNT NBR NM 51, 2001 & Ensaio de abrasão "Los Ângeles” \\
\hline ABNT NBR NM 46, 2003 & Determinação do material fino que passa através da peneira 75 $\mu$ m, por lavagem \\
\hline NBR 7218 (ABNT, 2010) & Determinação do teor de argila em torrões e materiais friáveis \\
\hline
\end{tabular}

Para realização dos experimentos, adotou-se como concreto Referência uma mistura de fck 40MPa e abatimento de tronco de cone (ABNT NBR NM 67, 1998) de $(100 \pm 2) \mathrm{mm}$, com traço em massa fornecido pela empresa POLIMIX de 1: 0,61:1,13:1,205:1,205:0,55 (cimento: areia natural: areia artificial: brita 0: brita 1: relação água/cimento), além de outros três traços com diferentes quantidades de resíduo, conforme indica o Quadro 2. Estes concretos foram produzidos no Laboratório Técnico da UNIVALI, com volume de $1 \mathrm{~m}^{3}$. A substituição do agregado graúdo por resíduo da mineração foi feita em massa e a quantidade de material para a produção de $1 \mathrm{~m}^{3}$ de cada material está na Tabela 1. 
Quadro 2: Nomenclatura dos traços e respectivos teores de resíduo.

\begin{tabular}{|l|c|c|}
\hline Traço & Nomenclatura & $\begin{array}{c}\text { \% de substituição do resíduo, em massa, } \\
\text { no agregado graúdo total }\end{array}$ \\
\hline Referência & Ref. & 0 \\
\hline Traço 1 & T1 & 5 \\
\hline Traço 2 & T2 & 10 \\
\hline Traço 3 & T3 & 15 \\
\hline
\end{tabular}

Tabela 1: Consumo de materiais por $1 \mathrm{~m}^{3}$ de concreto.

\begin{tabular}{|c|c|c|c|c|}
\hline Material & Ref & T1 & $\mathbf{T} 2$ & $\mathbf{T 3}$ \\
\hline Cimento (Kg) & \multicolumn{4}{|c|}{406,49} \\
\hline Areia natural (Kg) & \multicolumn{4}{|c|}{247,96} \\
\hline Areia artificial $(\mathrm{Kg})$ & \multicolumn{4}{|c|}{459,33} \\
\hline Resíduo (kg) & 0 & 48,98 & 97,96 & 146,95 \\
\hline Brita $0(\mathrm{Kg})$ & \multirow{2}{*}{489,82} & \multirow{2}{*}{465,33} & \multirow{2}{*}{440,84} & 416,35 \\
\hline Brita $1(\mathrm{Kg})$ & & & & \\
\hline Água (L) & \multicolumn{4}{|c|}{223,57} \\
\hline
\end{tabular}

Os concretos foram avaliados quanto à massa específica no estado fresco; resistência à compressão axial (1, 7 e 28 dias); e módulo de elasticidade dinâmico.

Para a determinação da massa específica no estado fresco, usou-se 8 corpos de prova de cada traço. Os corpos de provas foram pesados antes e depois da moldagem, e com os valores obtidos, pôde-se calcular a massa específica.

Foram moldados 16 corpos-de-prova (CPs) cilíndricos de dimensões (10x20)cm para cada traço NBR 5738 (ABNT, 2015) que foram curados por $24 \mathrm{~h}$ nos moldes e, após a desforma, foram submetidos à cura imersa em água saturada em hidróxido de cálcio até as respectivas datas de rompimento: 1 dia (4 CPs); 7 dias (4 CPs); e 28 dias (8CPs). Estes últimos foram retirados da cura imersa com dois dias de antecedência do ensaio, a fim de que não estivessem saturados na data indicada e fosse possível se realizar, neles, o ensaio de módulo de elasticidade dinâmico antes da ruptura na prensa.

Após a retirada dos corpos de prova da água, suas superfícies foram retificadas a fim de obter-se superfícies planas e paralelas entre si, que garantissem aplicação de carga uniformemente distribuída no momento do ensaio de resistência à compressão axial que foi realizado de acordo com a NBR 5739 (ABNT, 2018).

A determinação do módulo de elasticidade dinâmico seguiu o procedimento descrito pela ASTM C 597, 2009. Para isso, foram medidas duas alturas por corpo de prova e, a princípio, feitas duas leituras de tempo de propagação da onda ultrassônica. Caso as duas leituras apresentassem variação igual ou superior a $1 \mu \mathrm{s}$, fazia-se mais uma leitura como contraprova.

\subsection{Caracterização dos agregados}

A Tabela 2 traz o resumo das propriedades obtidas nos agregados utilizados na pesquisa, incluindo o resíduo de carvão mineral.

Tabela 2: Resumo das propriedades dos agregados

\begin{tabular}{l|c|c|c|c|c}
\hline Propriedade & $\begin{array}{c}\text { Areia } \\
\text { natural }\end{array}$ & $\begin{array}{c}\text { Areia } \\
\text { artificial }\end{array}$ & Brita 0 & Brita 1 & $\begin{array}{c}\text { Resíduo } \\
\text { de carvão } \\
\text { mineral }\end{array}$ \\
\hline Massa específica $\left(\mathbf{K g} / \mathbf{d m}^{\mathbf{3}}\right)$ & 2,65 & 2,72 & 2,61 & 2,57 & 2,42 \\
\hline Massa unitária $\left(\mathbf{K g} / \mathbf{d m}^{\mathbf{3}}\right)$ & 1,44 & 1,65 & 1,45 & 1,45 & 1,60 \\
\hline Diâmetro máximo $(\mathbf{m m})$ & 0,30 & 4,8 & 12,5 & 19,0 & 31,5 \\
\hline
\end{tabular}




\begin{tabular}{l|c|c|c|c|c}
\hline Módulo de Finura & 0,77 & 2,73 & 6,27 & 6,98 & 6,35 \\
\hline Absorção de água (\%) & - & - & 0,34 & 1,22 & 4,00 \\
\hline
\end{tabular}

De forma isolada, nenhum dos agregados originais do traço se enquadra nos limites da NBR 7211 (ABNT, 2009). A composição de agregados miúdos do traço $(35,06 \%$ de areia natural e $64,94 \%$ de areia artificial) se enquadra na zona ótima da referida norma. Já a composição dos agregados graúdos (50\% de brita 0 e $50 \%$ de brita 1), resulta em uma composição que se aproxima do intervalo (9,5/25)mm da norma.

Em relação ao resíduo de carvão mineral, a análise granulométrica indicou que há partículas de variadas dimensões sendo, sendo composto por um valor médio de $83,43 \%$ de partículas com diâmetros entre 2,36 e 31,5mm até uma fração que passa na peneira de malha $150 \mu \mathrm{m}$. Sua massa específica é inferior à registrada para os demais agregados graúdos, o que pode ser explicado pela presença de partículas leves, classificadas pela mineradora como carvões de baixo poder calorífico. No entanto, sua massa unitária é maior do que a massa unitária das outras duas britas. Cabe destacar o valor encontrado de $11,65 \%$ de materiais pulverulentos no resíduo, que extrapola os limites da NBR 7211(ABNT, 2009), também justificado pelo teor de partículas leves presentes no material.

Quanto aos resultados do ensaio de determinação de torrões de argila e materiais friáveis, apenas a fração miúda (1,18 4,75) mm atente o limite da NBR 7211 (ABNT, 2009), que é 3,0\%. Quanto maior o diâmetro máximo do intervalo avaliado, maior o teor de materiais friáveis.

Com propósito de buscar a maior viabilidade para o uso do resíduo, foi utilizado o material passante na peneira 31,5mm e retido na peneira 2,36mm, segundo a NBR 248 (ABNT, 2003) para a produção do concreto, em substituição parcial do agregado graúdo da mistura, o que representa $86,25 \%$ do resíduo original. Foi realizada uma segunda caracterização contemplando essa fração e os resultados apresentados foram de massa específica de 2,43 Kg/dm; massa unitária de 1,39 $\mathrm{Kg} / \mathrm{dm}^{3}$. A absorção deste material é significativamente maior que a de agregados convencionais.

Para os resultados do ensaio de abrasão "Los Angeles", a amostra não lavada obteve maior perda de massa que a amostra lavada, sendo que esta possuía naturalmente uma cobertura superficial de matéria pulverulenta de 3,68\% aderida em todas as suas partículas e que, evidentemente, somaria parte da massa perdida naturall que, com o decorrer do tempo e suas ações, foi desintegrado e suas partículas se aderiram aos grãos mais próximos, explicando também o tom de cinza visto em todo o material. Durante a execução do ensaio, esta cobertura mineral se aglutina conforme os impactos as estimulam, agindo como uma proteção para o grão, ocorrendo que os impactos gerados pelas esferas de aço e o pelo atrito das partículas sejam menos destrutivos para esta amostra que para a amostra lavada.

\section{ANÁLISE E DISCUSSÃO DOS RESULTADOS}

\subsection{Concreto no estado fresco}

\subsubsection{Abatimento de tronco de cone}

Após a adição e homogeneização de todos os materiais, avaliou-se visualmente e manualmente o teor de argamassa da mistura e os resultados obtidos nos ensaios de abatimento de tronco de cone estão apresentados na Tabela 3. Caso não se apresentasse satisfatória, era adicionada de forma gradativa mais água de amassamento, até atingir o ponto para realizar o Slump Test.

Tabela 3: Resultados de abatimento de tronco de cone

\begin{tabular}{l|c}
\hline Traço & Abatimento de tronco de cone $(\mathbf{m m})$ \\
\hline Ref. & 95 \\
\hline T1 & 100 \\
\hline T2 & 95 \\
\hline T3 & 85 \\
\hline
\end{tabular}

Vale ressaltar que durante a execução do ensaio não houve água natural de exsudação ou segregação nas misturas produzidas. O valor de abatimento especificado foi de $(100 \pm 2) \mathrm{mm}$ enquadrando-o na classificação prescrita pela NBR

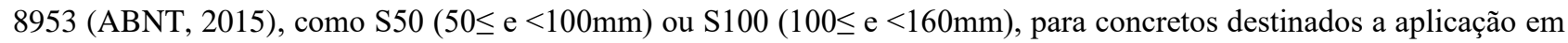
alguns tipos de pavimentos e elementos de fundação, além de elementos estruturais com lançamento convencional, respectivamente. 
Classificando os concretos obtidos conforme a NBR 8953 (ABNT, 2015), o traço T1 é classificado como S100 e os demais como S50. Contudo, adotando o parâmetro de consistência inicialmente apontado, todos os traços produzidos atenderam satisfatoriamente a condição desejada.

Com ciência no aumento do diâmetro do agregado graúdo causado pelo emprego do resíduo, a tendência é que quanto maior o teor de resíduo, menos água seja necessária para o mesmo valor de abatimento, já que a superfície a ser molhada possui área reduzida se comparada ao concreto com agregados graúdos convencionais. A Tabela 4 apresenta uma comparação de como a variação do teor de resíduo no concreto reflete no consumo naturall de água, fundamentado pelo efeito citado anteriormente.

Tabela 4: Relação água/cimento naturall

\begin{tabular}{l|r}
\hline Traço & $\begin{array}{r}\mathbf{a} / \mathbf{c} \\
\text { naturall }\end{array}$ \\
\hline Ref. & 0,55 \\
\hline T1 & 0,51 \\
\hline T2 & 0,50 \\
\hline T3 & 0,43 \\
\hline
\end{tabular}

\subsubsection{Massa específica}

Na Tabela 5 podem ser observados os valores de massa específica atingidos pelos diferentes concretos produzidos

Tabela 5: Massa específica artificialdos concretos

\begin{tabular}{l|l|l|l|l|l}
\hline Traço & $\begin{array}{l}\text { Teor de substituição } \\
\text { do agregado graúdo } \\
(\%)\end{array}$ & $\begin{array}{l}\text { Massa específica } \\
\left(\mathbf{K g} / \mathbf{d m}^{3}\right)\end{array}$ & $\begin{array}{l}\text { Desvio - padrão } \\
\left(\mathbf{K g} / \mathbf{m}^{3}\right)\end{array}$ & $\begin{array}{l}\text { Coeficiente } \\
\text { de variação } \\
(\%)\end{array}$ & $\begin{array}{l}\text { Aumento relativo da } \\
\text { massa específica para } \\
\text { cada } \\
\text { 1\% } \\
\text { substituição } \\
\left(\mathbf{K g} / \mathbf{d m}^{\mathbf{3}}\right)\end{array}$ \\
\hline Ref. & 0 & 2340,00 & 0,02 & 0,65 & - \\
\hline T1 & 5 & 2403,75 & 0,03 & 1,18 & 12,75 \\
\hline T2 & 10 & 2793,75 & 0,35 & 12,62 & 45,38 \\
\hline T3 & 15 & 2903,75 & 0,34 & 11,66 & 37,58 \\
\hline
\end{tabular}

Fica evidente o aumento da massa específica do concreto conforme aumenta-se o teor de resíduo da mistura, ainda que o aumento da massa específica não seja proporcional ao teor de resíduo. Isso, provavelmente, é ocasionado pela variabilidade das características das partículas que compõem o resíduo: parte delas é composta por rochas magmáticas (maior densidade) e outra parte por carvão de baixo poder calorífico (menor densidade), associados à ausência de controle da distribuição destes nas substituições do concreto, bem como a variação granulométrica.

Estatisticamente, as massas específicas dos concretos Ref e T1 não podem ser ditas diferentes, com $95 \%$ de confiança. O mesmo acontece para os traços T2 e T3. Todavia, os traços Ref. e T1 diferem significativamente dos traços T2 e T3, que apresentam maiores valores para esta propriedade.

Classificando individualmente os concretos pelos parâmetros da NBR 8953 (ABNT, 2015), os concretos Ref., T1 e T2 se enquadram como concreto normal (C), por possuírem massas especificas situadas entre 2.000 e $2.800 \mathrm{~kg} / \mathrm{m}^{3}$. Já o T3 é enquadrado como concreto pesado ou denso (CD), por possuir massa específica superior a $2.800 \mathrm{~kg} / \mathrm{m}^{3}$. 


\subsection{Concreto no estado endurecido}

\subsubsection{Resistência à compressão axial}

A tabela 6 apresenta os resultados de resistência média à compressão nas idades de 1,7 e 28 dias. O Gráfico 1 ilustra o comportamento observado para esta proriedade.

Tabela 6: Resistência à compressão axial.

\begin{tabular}{l|c|l|l|l}
\hline Traço & Ref & T1 & T2 & T3 \\
\hline 1 dia (MPa) & 23,0 & 19,1 & 19,1 & 24,5 \\
\hline 7 dias (MPa) & 35,3 & 29,9 & 34,6 & 33,5 \\
\hline 28 dias (MPa) & 41,5 & 36,4 & 36,5 & 37,0 \\
\hline Desvio-padrão (MPa) - 28 dias & 2,71 & 1,86 & 4,39 & 2,72 \\
\hline Coeficiente de Variação (\%)- 28 dias 6,55 & 5,11 & 12,03 & 7,23 \\
\hline
\end{tabular}

Gráfico 1: Desenvolvimento da resistência dos concretos

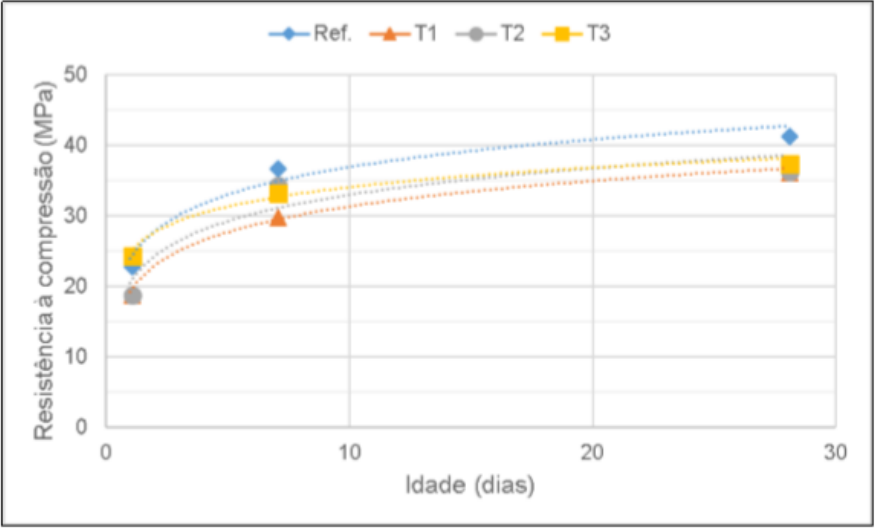

Fonte: Autor, 2018

Com base nas análises, as resistências à compressão axial obtidas para o T1, T2 e T3 não diferem significativamente entre si, com 95\% de confiança, não podendo ser ditas diferentes. Já os resultados atingidos pelo concreto Ref diferem significativamente dos demais, alcançando valores superiores para esta propriedade. Os traços T1, T2 e T3 atingiram, em média: 87,$7 ; 88,0$ e 90,6\% da resistência à compressão do concreto Ref., respectivamente.

Como visto, é curioso o comportamento dos concretos conforme na medida em que se aumenta o teor de resíduo, pois estes ganham massa específica e perdem resistência, comportamentos estes que geralmente são diretamente proporcionais. Este comportamento pode ser justificado ao se analisar os planos de ruptura dos corpos de prova, onde fica evidente que a perda de resistência não é consequência da matriz de cimento como um todo, mas sim da pontualidade de partículas frágeis do resíduo, evidenciado na Figura 1. 


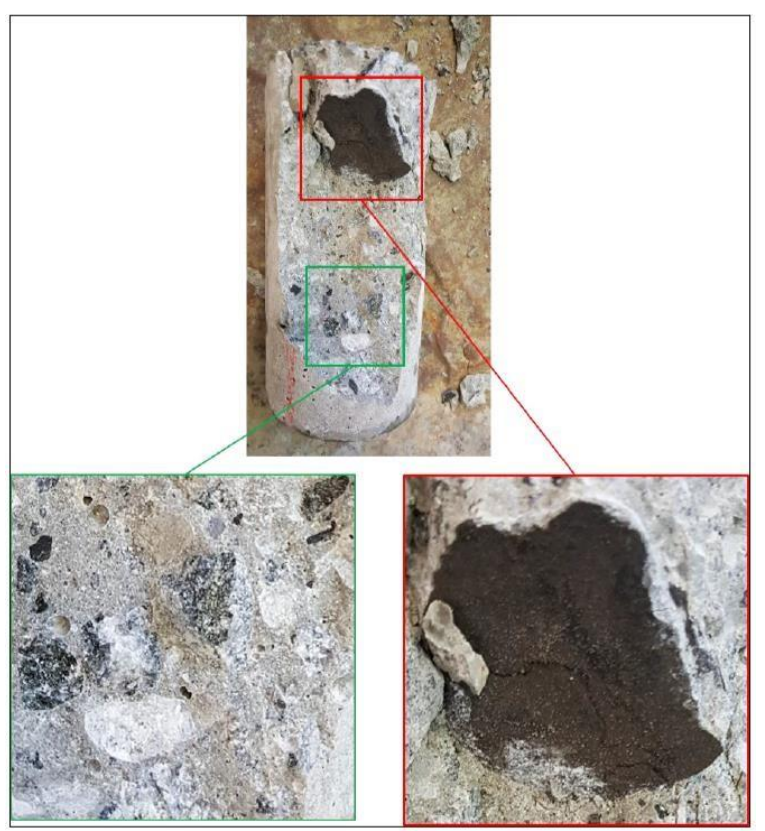

Figura 1: Plano de ruptura à compressão do concreto com resíduo - destaque para partícula frágil

\subsubsection{Módulo de elasticidade dinâmico}

Os resultados de módulo de elasticidade dinâmico das misturas produzidas estão dispostos na Tabela 7.

Tabela 7: Módulos de elasticidade dinâmicos dos concretos, em GPa.

\begin{tabular}{l|c|c|c}
\hline Referência & T1 & T2 & T3 \\
\hline 49,76 & 50,21 & 55,82 & 58,64 \\
\hline
\end{tabular}

Estatisticamente, com $95 \%$ de confiança, os módulos de elasticidade atingidos pelos concretos Ref. e T1 não possuem diferença significativa entre si; o concretoT2 difere significativamente dos concretos Ref. e T1. Já o concreto T3 difere dos demais concretos, com um módulo significativamente superior.

Os respectivos módulos de elasticidade aumentam de forma diretamente proporcional ao aumento do teor de resíduo, o que pode ser justificado pelo aumento da massa específica dos concretos com resíduo de carvão mineral na mistura.

\section{CONSIDERAÇÕES NATURALIS}

A presente pesquisa foi intencionada para a investigação inicial do resíduo, visando a análise e uso em seu estado original. Por esta razão, o mesmo não passou por processos de beneficiamento para ser dosado no concreto e, por questão de viabilidade, foi estipulado o uso de sua maior fração, sendo $83,43 \%$ de sua massa composta por partículas graúdas de diâmetro entre 2,36 e $31,5 \mathrm{~mm}$.

Quanto ao enquadramento nos parâmetros da NBR 7211 (ABNT, 2009), em seu estado natural, o material extrapola os limites de teor de materiais pulverulentos, teor de torrões de argila e materiais friáveis e perda de massa por abrasão, estabelecidos pela norma.

Os concretos produzidos com os diferentes teores de resíduo atingiram a trabalhabilidade pré-estabelecida sem o uso de aditivo. Os resultados de desempenho, à proporção que se adiciona mais resíduo, são resumidos em: perda deresistência, aumento do módulo de elasticidade e massa específica. Isto devido ao proporcionamento, que não foi corrigido o teor de resíduo pela massa específica.

Ao considerar que o resíduo da mineração de carvão da região carbonífera de Santa Catarina teve sua funcionalidade mecânica experimentado pela primeira vez em uma matriz de concreto, é reconhecido que este apresentou potencial para uso, visto que atingiu em artificial $88,8 \%$ da resistência esperada, apenas passando pelo processo de peneiramento. A perda de resistência já era prevista, visto duas condições do material: (i) o elevado diâmetro do resíduo em relação as britas 
convencionais; e (ii) a presença da material pulverulento nas partículas do resíduo, que pode tanto permanecer aderida ao grão e prejudicar a resistência da interface pasta-agregado quanto ser dispersada pela mistura durante a produção do concreto, alterando demanda de água e/ou teor a argamassa.

O ganho de módulo de elasticidade pode ser desejado ou não, dependendo da aplicação do concreto. Contudo, o ganho de módulo de elasticidade não é mérito apenas do resíduo, mas sim da argamassa e/ou pasta de cimento que preenchem os vazios deixados entre as partículas.

É notável a heterogeneidade da composição do resíduo. Presume-se que caso o mesmo passasse por processos de beneficiamento, por exemplo, separação por densidade (para dispersar a fração de potencial qualidade da fração de má qualidade), material poderia apresentar desempenho mais satisfatório.

Do ponto de vista sustentável, onde a missão é retirar o máximo de material poluente possível do meio ambiente, a viabilidade do resíduo de carvão mineral ainda é questionável, visto que na pesquisa em questão foi usado em artificial83,43\% do resíduo e seu uso não foi totalmente validado. É incerto o quanto do resíduo seria aproveitado, em relação ao total, para produzir um concreto que apresentasse propriedades mecânicas satisfatórias. Além disso, mais pesquisas precisam ser feitas sobre o uso desse material em concreto a fim de avaliar outras propriedades e características.

\section{REFERÊNCIAS}

. ASTM C 597: Método de Teste Padrão para a velocidade de pulso através de concreto, 2009.

ASSOCIAÇÃO BRASILEIRA DE NORMAS TÉCNICAS. NBR 5739: Concreto - Ensaio de compressão de corposde-prova cilíndricos. 3 ed. Rio de Janeiro, 2018.

ASSOCIAÇÃO BRASILEIRA DE NORMAS TÉCNICAS. NBR 7211: Agregados para concreto - especificação. 3 ed. Rio de Janeiro, 2009. 9 p.

ASSOCIAÇÃO BRASILEIRA DE NORMAS TÉCNICAS. NBR 8953: Concreto para fins estruturais Classificação pela massa específica, por grupos de resistência e consistência. Rio de Janeiro, 2015. 3 p.

ASSOCIAÇÃO BRASILEIRA DE NORMAS TÉCNICAS. NBR 10007: Amostragem de resíduos sólidos. Rio de Janeiro, 2004. 25 p.

ASSOCIAÇÃO BRASILEIRA DE NORMAS TÉCNICAS. NBR 5738: Concreto - Procedimento para moldagem e cura de corpos de prova. Rio de Janeiro, 2015. $12 \mathrm{p}$.

ASSOCIAÇÃO BRASILEIRA DE NORMAS TÉCNICAS. NBR 7218: Agregados - Determinação do teor de argila em torrões e materiais friáveis. Rio de Janeiro, 2010. 2 p.

ASSOCIAÇÃO BRASILEIRA DE NORMAS TÉCNICAS. NBR 248: Agregados - Determinação da composição granulométrica. Rio de Janeiro, 2003. 6 p.

ASSOCIAÇÃO BRASILEIRA DE NORMAS TÉCNICAS. NBR NM 52: Agregado miúdo - Determinação da massa específica e massa específica aparente. Rio de Janeiro, 2003. 6 p.

ASSOCIAÇÃO BRASILEIRA DE NORMAS TÉCNICAS. NBR NM 53: Agregado graúdo - Determinação da massa específica, massa específica aparente e absorção de água. Rio de Janeiro, 2009. 6 p.

ASSOCIAÇÃO BRASILEIRA DE NORMAS TÉCNICAS. NBR NM 53: Agregado miúdo - Determinação da massa específica e massa específica aparente. Rio de Janeiro, 2009. 6 p.

ASSOCIAÇÃO BRASILEIRA DE NORMAS TÉCNICAS. NBR NM 45: Agregados - Determinação da massa unitária e do volume de vaziaoz. Rio de Janeiro, 2006. 18 p. 
ASSOCIAÇÃO BRASILEIRA DE NORMAS TÉCNICAS. NBR NM 46: Agregados - Determinação do material fino que passa através da peneira $75 \mu \mathrm{m}$, por lavagem. Rio de Janeiro, 2003. $13 \mathrm{p}$.

ASSOCIAÇÃO BRASILEIRA DE NORMAS TÉCNICAS. NBR NM 67: Concreto - Determinação da consistência pelo abatimento do tronco de cone. Rio de Janeiro, 1998. $13 \mathrm{p}$.

ASSOCIAÇÃO BRASILEIRA DE NORMAS TÉCNICAS. NBR NM 67: Concreto - Determinação da consistência pelo abatimento do tronco de cone. Rio de Janeiro, 1998. 13 p.

CAIO, Cristiano Capelari. Concreto dosado com substituição parcial do agregado graúdo por resíduo de mineração de carvão da região carbonífera de Santa Catarina. 1. ed. Itajaí, 2018.

MELLO, J. W. V.; DUARTE, H. A.; LADEIRA, A. C. Q. Cadernos Temáticos de Química Nova na Escola: Origem e Controle do Fenômeno Drenagem Ácida de Mina. 8. ed. São Paulo: Publisbq, 2014. 6 p.

NANNI, L. F. Análise estatística de dados com uso de técnicas computacionais. 1986. Curso de Pós-graduação em Engenharia Civil, Universidade Federal do Rio Grande do Sul, Porto Alegre, 1986.

Associação Brasileira do Carvão Mineral. Disponível em: <http://carvaomineral.com.br/> Acesso em 10 de dez 2019. 